\title{
Leadership and the Art of Social Persuasion
}

\author{
Effie Heotis ${ }^{1^{*}}$
}

${ }^{1}$ Grand Canyon University, Phoenix

Received: May 15, 2017; Accepted: June 9, 2017; Published: June 21, 2017

*Corresponding author: Effie Heotis, Grand Canyon University, Phoenix. E-mail: eheotis@yahoo.com

\section{Abstract}

In response to today's increasingly globalized and complex world, organizations and communities look at ways in which leadership attributes move people into action. Ample leadership research suggests that ideal leadership styles inspire and mobilize others through an exemplary set of dispositions and behaviors. The conceptualization of social persuasion is characterized by these features. This paper aims at providing more illumination on effective leadership by discussing essential elements associated with elements that are pivotal for effective leadership. The mark of a refined leader is a clear vision and inspires others to commit to the realization of that vision by elevating consciousness individually and collectively.

Key Words: Leadership, Self-Reflection, Personal Growth Interpersonal Skills, Interpersonal Relationships

\section{Leadership and the Art of Social Persuasion}

In response to today's increasingly globalized and complex world, organizations and communities look at ways in which leadership attributes move people into action. Ample leadership research suggests that ideal leadership styles inspire and mobilize others through an exemplary set of dispositions and behaviors. The conceptualization of social persuasion is characterized by these features. This paper aims at providing more illumination on effective leadership by discussing essential elements associated with elements that are pivotal for effective leadership. The mark of a refined leader is a clear vision and inspires others to commit to the realization of that vision by elevating consciousness individually and collectively for the sake of the greater good.

\section{Leaders as Social Mirrors}

Effective leaders transform by modeling that which inspires others to motivationally change behaviors, attitudes and aspects of their lives [1]. The disposition of a leader influences members of a given group through interpersonal connections that instill a sense of community and unity. The ideal role of a leader exhibits exemplary qualities that transfer onto the community setting. Leaders serve as role models to guide and inspire others in emulating and engaging in a certain set of behaviors and attitudes [1,7].

\section{Inspiration for Social Change}

Behaviors that signify transformation of others-rather than transactional relationships-as indicated by expressions relevant to interpersonal styles and work ethic, serve as exemplars to inspire and motivate a workforce in collectively and actively working toward achieving a community's goals [7]. Heightened self-awareness and interpersonal skills, as reflected in relation to the self and others, are crucial in establishing credibility among relationships [6]. Lilienfeld, et al. assert that emanation of high levels of confidence and clarity when sharing a vision is linked to adaptive functioning that leads to social success among high level leadership positions [5]. Leaders serve as mirrors for their community by reflecting their values, attitudes and behaviors associated with realizing their visions therefore, it is important that leaders practice mindfulness of the means employed for social persuasion $[1,4]$.

\section{Organizational Change Occurs Through Social Change}

Organizational change occurs through social change via transformational styles of leadership [1,3,7]. Effective leaders raise consciousness by inspiring others to transcend above their own needs for the sake of their community or organization. Vasillopulos and Denney maintain that responsible leadership is synonymous with effective leadership; furthermore, such leaders impose moral codes that serve beyond self-interest and focus on the best interest of society at large [8].

\section{Elevating Consciousness for Transformation}

Interpersonal components associated with a transformational style are emergent and adaptive in a challenging and globalizing work environment [7]. Effective leaders instill a strong sense of community, higher purpose and elevate consciousness to ensure realization of a vision that serves the community as a whole. Good leaders develop through a life-long process from on a combination of self-study and an openness to reflective, experiential learning from other people, places and situations $[1,6]$. The foundations of leadership transpire through personal growth via the merging of educational, professional 
and personal developmental experiences that facilitate elevated levels of clarity and reflection of one's interpersonal skills, values and belief systems. In light of this, the emphasis for leadership development is derived from self-assessment through reflective learning rather than assessment of one's capabilities through introspective thought. Opportunities for leadership development arise from the evaluation of problem solving practices and outcomes through connections with communities [3]. Lilienfeld, et al. discuss certain features related to boldness-perceived from members of the community as confidence, purpose and assurance in realization of visions-are reflected in higher ratings of presidential performance among Presidents of the United States [5]. In other words, communicating confidence in achieving a higher purpose among leaders is associated with social support, success and ideal leadership outcomes.

\section{Interpersonal Skills for Social Leadership}

Social leadership employs interpersonal skills to effectively communicate and collectively realize visions through affiliation, experimentation, innovation and sharing of learning experiences [1]. Through social persuasion, an individual is able to reach within and also reach across a wide set of diverse populations to change a social or cultural system.

\section{Establishing Vision through Connection}

Lilienfeld, et al. asserts that the dimension that dominates fear, as it is associated with strong articulation of vision, fosters adaptive leadership behaviors and interpersonal success [5]. In addition, leaders that clearly communicate confidence in a vision coincided with other relevant dimensions such as effective leadership, persuasiveness, taking initiative and willingness to take risks to achieve a goal. Effective relations, established connections and clear communications with diverse populations and settings is a pinnacle for interpersonal success [2,6]. van Eeden, et al. posit that leaders engaged in people oriented roles are more likely to move people compared to leaders that are oriented towards tasks [7]. As a means of social persuasion, leaders are dynamically tied to members of a community [2]. Consequently, members of a community gain confidence in leaders, as members relate to and identify with leaders' values and attitudes [7].

\section{Conclusion}

The concept of leadership carries an enduring sense of unity. Reaching far beyond self-interests, a refined leader gives rise to self-motivated changes within others that ultimately have a profound impact on a given organization or community. Interpersonal and transformational types of exchanges are vital in persuading members of a community to collectively commit to a plan of action [2]. Therefore, it is imperative for leaders to strengthen the power of community and engage collectively towards a shared vision that serves a purpose for the greater good. Social persuasion contains elements that strengthen the collective power in a rapidly changing and globalizing world- one that requires more innovative collaboration and elevated consciousness for solving complex problems.

\section{References}

1. Brown LM, BZ Posner. Exploring the relationship between learning and leadership. The Leadership \& Organization Development Journal. 2001;22(6):274-280.

2. Hoppe B, Reinelt C. Social network analysis and the evaluation of leadership networks. The Leadership Quarterly. 2010;21(4):600-619. doi: 10.1016/j.leaqua.2010.06.004

3. Kinsella S, Wood N. University/community partnerships: Engaging business students in leadership and solution-based approaches. Journal of Management Policy and Practice. 2014;15(3):36-41.

4. Krohn A. Intrapsychic impediments to effective leadership. Psychoanalytic Inquiry. 2012;32(4):358-367. doi: 10.1080/07351690.2011.609367

5. Lilienfeld SO, Waldman ID, Landfield K, Watts AL, Rubenzer S, Faschingbauer TR. Fearless dominance and the U.S. presidency: implications of psychopathic personality traits for successful and unsuccessful political leadership. J Pers Soc Psychol. 2012;103(3):489505. doi: $10.1037 / \mathrm{a} 0029392$

6. Odom SF, Boyd BL, Williams J. Impact of personal growth projects on leadership identity development. Journal of Leadership Education. 2012;11(1):49-63.

7. van Eeden R, Cilliers F, van Deventer V. Leadership styles and associated personality traits: Support for the conceptualisation of transactional and transformational leadership. South African Journal of Psychology. 2008;38(2):253-267.

8. Vasillopulos C, Denney M. Moral responsibility: The missing element in educational leadership. Higher Education Studies. 2013;3(2):74-85. doi: 10.5539/hes.v3n2p74 